\title{
Ion Implantation and Annealing of SrTi03 and CaTiO3
}

\section{Citation}

Aziz, Michael J., L. A. Boatner, J. Rankin, and C. W. White. 1987. Ion Implantation and Annealing of SrTiO3 and CaTiO3. Materials Research Society Symposium Proceedings 93: 9-13.

\section{Published Version}

http://www.mrs.org/s_mrs/sec.asp?CID=1727\&DID=38980

\section{Permanent link}

http://nrs.harvard.edu/urn-3:HUL.InstRepos:2839216

\section{Terms of Use}

This article was downloaded from Harvard University's DASH repository, and is made available under the terms and conditions applicable to Other Posted Material, as set forth at http:// nrs.harvard.edu/urn-3:HUL.InstRepos:dash.current.terms-of-use\#LAA

\section{Share Your Story}

The Harvard community has made this article openly available.

Please share how this access benefits you. Submit a story.

Accessibility 
ION IMPLANTATION AND ANNEALING OF $\mathrm{SrTiO}_{3}$ AND $\mathrm{CaTHO}_{3}{ }^{\dagger}$

C.W. WHITE*, L.A. BOATNER*, J. RANKIN**, AND M.J. AZIZ***

* Oak Ridge National Laboratory, Oak Ridge, TN 37831

* Massachusetts Institute of Technology, Cambridge, MA 02139

*** Division of Applied Sciences, Harvard University, Cambridge, MA 02138

\section{ABSTRACT}

Ion implantation damage and thermal annealing results are presented for single crystals of $\mathrm{SrTiO}_{3}$ and $\mathrm{CaTiO}$. The near-surface region of both of these materials can be made amorphous by low doses $\left(\sim 10^{15} / \mathrm{cm}^{2}\right)$ of heavy ions ( $\mathrm{Pb}$ at $540 \mathrm{keV}$ ). During annealing, the amorphous implanted region crystallizes epitaxially on the underlying single-crystal substrate. The kinetics of this solid-phase epitaxial recrystallization process have been measured by employing ion channeling techniques.

\section{INTRODUCTION}

Ion implantation techniques are currently being extensively investigated as methods for altering the near surface optical, electrical, or mechanical properties of insulating materials.1- 6 Ion implantation processes generate extensive damage in the near-surface region of such materials; for a number of important applications it will be necessary to anneal the implanted insulating materials in order to remove or minimize the implantation-induced disorder. In contrast to the case of either $5 i$ or $G e$, there are only a few reported investigations of the effects of damage production associated with the implantation of insulating materials or their subsequent behavior during thermal annealing processes. Ion implantation is currently being used to modify the near-surface properties of a wide range of crystalline oxides and ceramic materials, $1,3,5,6$ and the response of these materials to ion bombardment and thermal annealing is being studied by means of ion channeling methods. In the present work, the response of two insulating materials, $\mathrm{SrTiO}_{3}$ and $\mathrm{CaTiO}_{3}$, to heavy ion bombardment and their behavior during subsequent thermal annealing will be described. The results show that moderate doses of $\mathrm{Pb}\left(\sim 1 \times 10^{15} / \mathrm{cm}^{2}\right)$ implanted at liquid nitrogen temperature are sufficient to render the near-surface region of single crystals of these titanates amorphous. Thermal annealing at temperatures $\left(<500^{\circ} \mathrm{C}\right)$ that are quite low in comparison to the melting points of these materials causes the near-surface region to recrystallize epitaxially on the underlying single crystal substrate. For both $\mathrm{SrTiO}_{3}$ and $\mathrm{CaTiO}_{3}$, the annealing process takes place by means of simple solid-phase epitaxy in which the amorphous-tocrystaline transformation occurs at a planar interface that moves toward the free surface of the material.

\section{EXPERIMENTAL DETAILS}

Single crystals of $\mathrm{CaTiO}_{3}$ and $\mathrm{SrTiO}_{3}$ were implanted with $\mathrm{Pb}$ ( $540 \mathrm{keV}$ ) to a dose of $1 \times 1015 / \mathrm{cm}^{2}$ at liquid nitrogen temperature. $\mathrm{CaTiO}_{3}$ has an orthorhombic structure and both low symetry (a- or c-axis oriented, with a - c) and high symetry (b-axis oriented) faces were tmpianted. $\mathrm{SrTHO}_{3}$

\footnotetext{
TResearch sponsored by the Division of Materials Sciences, U.S. Department of Energy under contract DE-AC05-840R21400 with Martin Marietta Energy Systems, Inc.
} 
has a cubic perovskite structure and crystals with a $\langle 100\rangle$ orientation were used primarily, although limited studies were carried out on crystals with a $\langle 110\rangle$ or $\langle 111\rangle$ orientation. Following implantation, the crystals were annealed in air at temperatures in the range of $270-500^{\circ} \mathrm{C}$ for time periads ranging from a few minutes to many hours. The crystals were examined in the as-implanted state and after thermal annealing using 2 MeV Rutherford backscattering and ion channeling techniques. Selected crystals of $\mathrm{CaTHO}_{3}$ were aiso examined by transmission electron microscopy (TEM).

\section{Results Obtained for $\mathrm{SrTiO}_{3}$}

Figure la shows that the implantation of a modest dose of $\mathrm{Pb}$ (540 keV, $\left.1 \times 1015 / \mathrm{cm}^{2}\right)$ into a (100) surface of $\mathrm{SrTHO}_{3}$ at liquid nitrogen temperature is suffictent to turn the near-surface region amorphous. In Fig. la, the aligned yield in the implanted region reaches the random value in the $\mathrm{Sr}$ sublattice and the step in the aligned yield from the $T i$ sublattice is equivalent to the increase in the random value at the energy corresponding to the $\mathrm{Ti}$ leading edge. The depth of the amorphous region in Fig. la is $\sim 1800 \mathrm{~A}$. Figure 10 shows that thermal annealing at $400^{\circ} \mathrm{C}$ for $30 \mathrm{~min}$ in air causes a significant reduction in the aligned yield from the implanted region demonstrating that the amorphous near surface layer has crystallized and is epitaxial with the underlying substrate. The aligned yield, however, is significantly higher than that in the virgin region showing that the recrystallized film is not defect free. Features in the aligned yield in both the $\mathrm{Sr}$ and $\mathrm{Ti}$ sublattices suggest that a dislocation network remains in the vicinity of the original amorphous/crystal interface after annealing. Positive identification of this structure is dependent on a detailed TEM examination.

(100) STTO, MPLANTEO BY PD $\left(540 \mathrm{kOV},\left(1210^{\left.1 \mathrm{~s} / \mathrm{cm}^{2}\right)}\right.\right.$ EPITAXIAL RECAYSTALLIzaTION
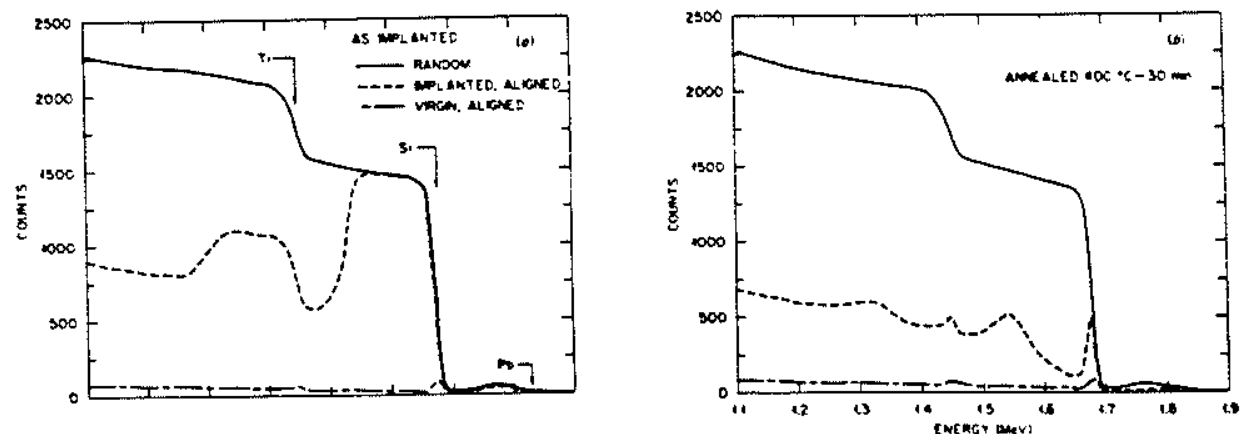

Fig. 1. Ion implantation and anneding of (100) $\mathrm{SrTiO}_{3}$. Ion channeling results are shown in la for the as-implanted state. Channeling results after annealing $\left(400^{\circ} \mathrm{C} / 30 \mathrm{~min}\right)$ are shown in 16 . 
Figure 2 shows results obtained after annealing (100) $\mathrm{SrTiO}_{3}$ at $302^{\circ} \mathrm{C}$ for 45 mins. Annealing for this time and temperature crystallizes about one half of the original amorphous region. Channeling measurements show that the near-surface region appears to be still amorphous but, as a result of annealing, the amorphous/crystalline interface has moved toward the surface by $\sim 800^{\circ} A$. This layer by layer crystallization is characteristic of the behavior expected when recrystallization takes place by simple solidphase epitaxy.

Figure 3 shows results obtained by annealing implanted $\mathrm{SrTiO}_{3}$ for different time periods at $302^{\circ} \mathrm{C}$. As the annealing time increases, the amorphous/crystalline interface moves toward the surface, but the recrystallized depth does not appear to be linear with time. Figure 4 shows the crystallized depth plotted as a function of annealing time at a temperature of $302^{\circ} \mathrm{C}$. These results show that during the initial stages of annealing there is little motion of the interface, but that after this ini$t i a l$ "induction period", the rate of interface motion becomes linear with a velocity of $\sim 0.91 \mathrm{~A} / \mathrm{sec}$. The induction period is a property of the crystallization process and is not simply related to the time required to raise the sample to the annealing temperature. The time required to bring the sample to the annealing temperature is much less than the induction time shown in Fig. 4.

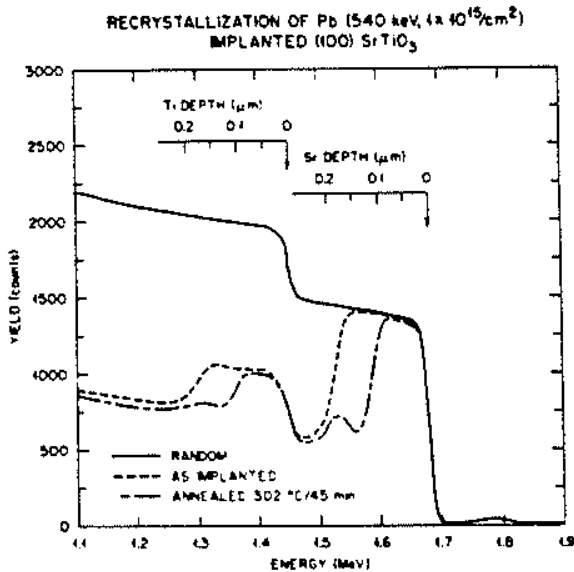

Fig. 2. Partial recrystallization of $\mathrm{Pb}$-implanted $\mathrm{SrTiO}_{3}$. Following implantation, the crystal was annealed at $302^{\circ} \mathrm{C}$ for $45 \mathrm{~min}$.

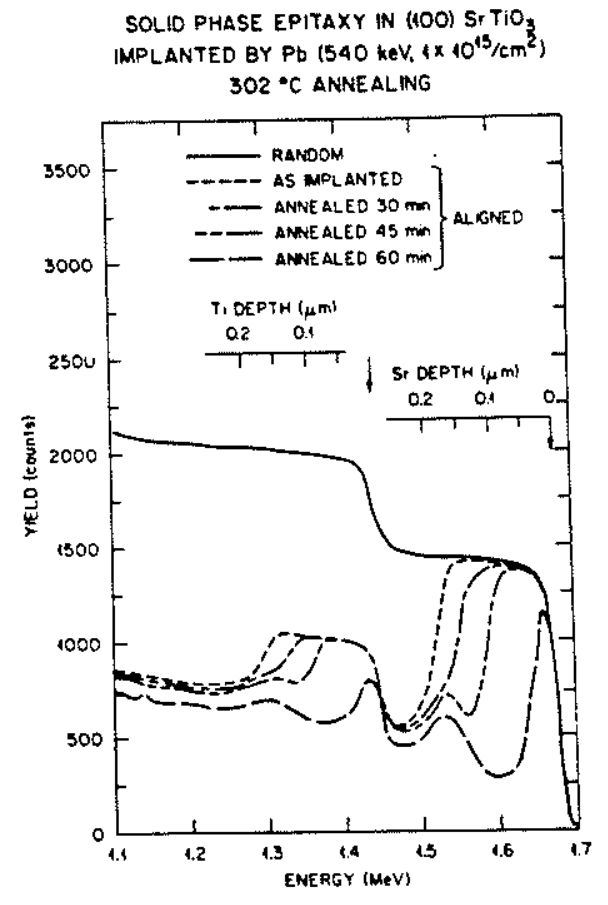

Fig. 3. Annealing of $\mathrm{Pb}-$ implanted $\mathrm{SrTHO}_{3}$. Channeling spectra are shown for several different annealing times.

Figure 5 shows the measured kinetics of crystallization for (100) $\mathrm{SrTiO}_{3}$ made amorphous by $\mathrm{Pb}$ implantation $\left(540 \mathrm{keV}, 1 \times 10^{15} / \mathrm{cm}^{2}\right)$ at liquid 
nitrogen temperature. In this figure, the measured crystallization rate determined from the jinear regrowth region is plotted on a $l 0 g$ scale as a function of inverse temperature. At each temperature, measurements of the recrystallized depth as a function of annealing time were made (similar to the results shown in Fig. 4). The growth velocities plotted in Fig. 5 were determined from the linear region of curves like the example shown in Fig. 4, following the induction period. Assuming a thermally activated process of the form $V(T)=V_{0} e^{-Q / R T}$, the data in the temperature range from $270-350^{\circ} \mathrm{C}$ can be fit reasonably well with an activation energy of $Q \sim 0.77 \mathrm{eV}$ and a prefactor $V_{0} \sim 5 \times 10^{-2} \mathrm{~cm} / \mathrm{sec}$.

In summary the results illustrated in Figs. 1-5 for $\mathrm{SrTiO}_{3}$ show that modest doses of $\mathrm{Pb}$ implanted at liquid nitrogen temperature are sufficient to turn the near-surface region amorphous and that thermal annealing at temperatures far below the $\mathrm{SrTiO}_{3}$ melting point can crystallize epitaxially the amorphous region. Crystallization takes place by solid-phase epitaxy (SPE) with an activation energy of $\sim 0.77 \mathrm{eV}$ as measured along the (100) direction. It is remarkable that simple layer-by-layer SPE can be observed in a material as complex as $\mathrm{SrTiO}_{3}$. The SPE process has long been studied in ion-implanted silicon, 10 but oxides such as $\mathrm{SrTiO}_{3}$ are much more complicated ternary systems. Nevertheless, the results obtained show that the simple SPE process can operate even in such complex materials. Preliminary measurements with $\langle 110\rangle$ oriented $\mathrm{SrTiO}_{3}$ single crystals suggest that the recrystallization kinetics along this direction are similar to those along the (100) direction. Initial experiments with <111> oriented crystals suggest that regrowth along this direction is not as well behaved as that observed along the (100) or (110) direction. This effect is being investigated further.

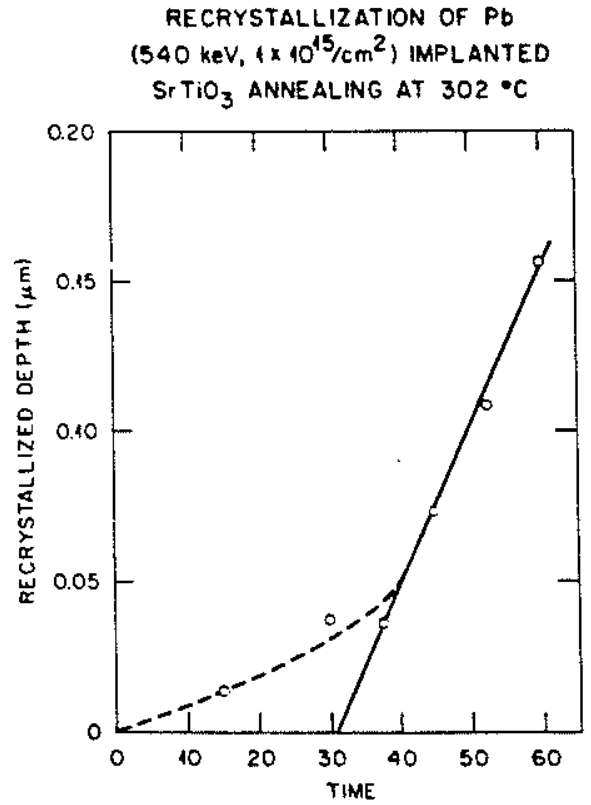

Fig. 4. Crystallized depth as a function of annealing time (min) for $\mathrm{SrTiO}_{3}$. A linear rate is observed following an induction period.
CRYSTALLIZATION OF AMORPHUS STTIO, AMORPHUS CRYSTAL TRANSFORMATION

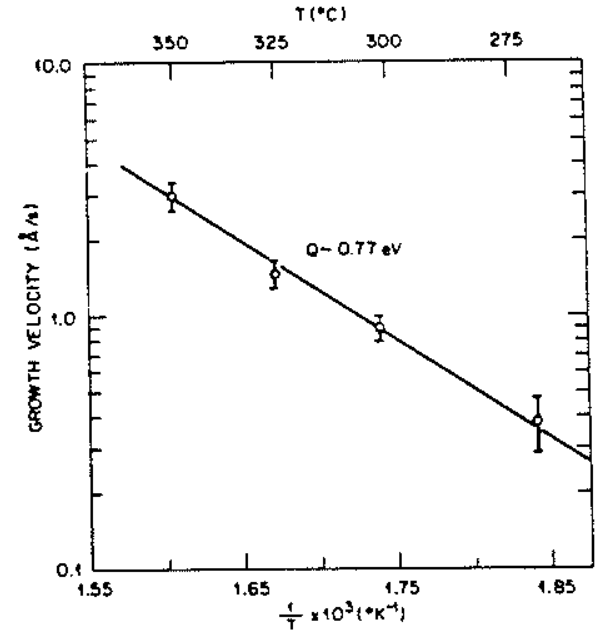

Fig. 5. Crystallization kinetics of (100) $\mathrm{SrTiO}_{3}$. Growth velocities are the linear rates measured following an induction period at each temperature. 
Results Obtained for $\mathrm{CaTiO}_{3}$

Another titanate that shows a relatively simple annealing behavior after ion beam induced amorphization is $\mathrm{CaTiO}_{3}$. This material has an orthorhombic structure and the near-surface region can easily be turned amorphous by the implantation of $\mathrm{Pb}$ at doses of $\sim 10^{15} / \mathrm{cm}^{2}$ at liquid nitrogen temperature. Annealing at temperatures much lower than the $\mathrm{CaTiO}_{3}$ melting point $\left(\sim 1950^{\circ} \mathrm{C}\right)$ produces epitaxial crystallization of the amorphous region.8,9 In this case also crystallization takes place by solid-phase epitaxy. Figure 6 shows the channeling results that demonstrate this behavior. In this case the implantation of $\mathrm{Pb}$ at $250 \mathrm{keV}$ creates an amorphous layer -1000 \& thick. After annealing $\left(440^{\circ} \mathrm{C} / 60 \mathrm{mins}\right)$, the amorphous/crystal interface has moved 2500 \& toward the surface, and the crystallized region is epitaxial with the underlying substrate.

Figure 7 shows a cross section micrograph demonstrating that crystallization of amorphous $\mathrm{CaTiO}_{3}$ occurs by solid-phase epttaxy. This micrograph was obtained from the near-surface region of $\mathrm{CaTiO}_{3}$ that is in the partially recrystallized state. In this case. Pb was implanted at $540 \mathrm{keV}$ (at liquid nitrogen temperature) to form an amorphous layer approximately 1850 A thick. After annealing $\left(480^{\circ} \mathrm{C} / 40\right.$ mins $)$ the amorphous/crystal interface has moved toward the surface by $\sim 500 \mathrm{~A}$. The crystallized layer is epitaxial with the underlying substrate and threading dislocations can be observed in this layer. After annealing, the amorphous/crystal interface is very sharp and planar (over many thousands of angstroms). This behavior is entirely consistent with that expected from solid-phase epitaxy.

The kinetics of crystallization as a function of temperature for growth along the low-symmetry direction in $\mathrm{CaTiO}_{3}$ have been determined previously. 8 These kinetics are consistent with an activation energy of $\sim 1.3 \mathrm{eV}$ for growth along this direction. Along the high-symetry direction (i.e., the pseudo cubic axis in $\mathrm{CaTiO}_{3}$ ) solid-phase epitaxy is observed (see Fig. 7) but the results suggest that a higher activation energy governs the growth in this direction.9 These results will be reported in detail in a later publication.

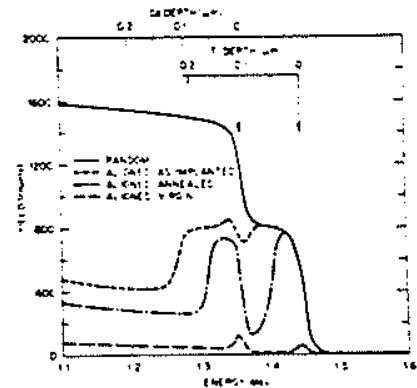

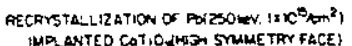

Fig. 6. Solid-phase epitaxy in $\mathrm{Pb}$-implanted $\mathrm{CaTiO}_{3}$ (highsymetry orientation). Annealing was carried out at $440^{\circ} \mathrm{C}$ for one hour. paptlal chystallization of tmmenteo cono,

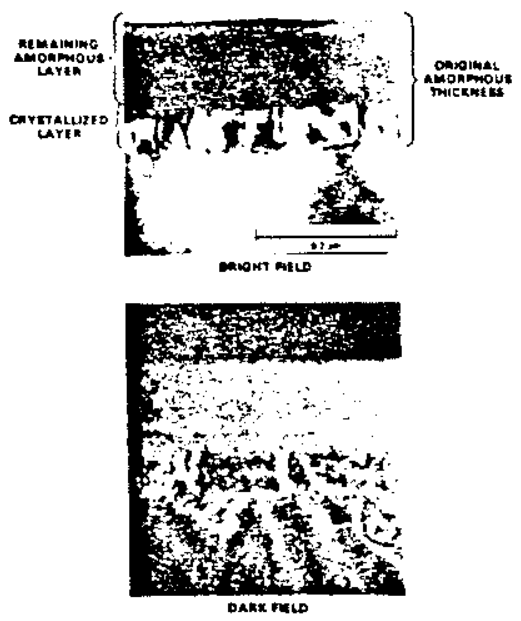

Fig. 7. Cross-section micrographs showing partial crystallization of $\mathrm{Pb}$-implantd $\mathrm{CaTiO}_{3}$ (high-symetry orientation). 
CONCLUSIONS

This implantation of $\mathrm{Pb}$ into both $\mathrm{SrTiO}_{3}$ and $\mathrm{CaTiO}_{3}$ produces an amorphous layer at doses as low as $\sim 1015 / \mathrm{cm}^{2}$. Annealing of these materials at temperatures far below their melting point gives rise to epitaxial crystallization of the amorphous layer and recrystallization of this amorphous layer takes place by solid-phase epitaxy. The activation energy measured for growth along the (100) direction in $\mathrm{SrTiO}_{3}$ is $\sim 0.77 \mathrm{eV}$. An activation energy of $\sim 1.3 \mathrm{eV}$ has been measured for growth along the lowsymetry direction of $\mathrm{CaTiO}_{3}$.

\section{REFERENCES}

1. C.J. McHargue, Nucl. Instrum. Methods B 19/20, 797 (1987).

2. M. Ohkubo, T. Hioki, and J. Kawamoto, J. Appl. Phys. 60, 1325 (1986).

3. C.J. Mchargue, C.W. White, B.R. Appleton, C.G. Farlow, and J.M. Williams, Mat. Res. Soc. Proc. 27, 385 (1984).

4. P.J. Burnett and T.F. Page, J. Mater. Sci. 19, 845 (1984).

5. H. Naramoto, C.W. White, J.M. Williams, C.J. MeHargue, O.W. Holl and, M.M. Abraham, and B.R. Appleton, J. Appl. Phys. 54, 683 (1983).

6. D. Poker, these proceedings.

7. C.W. White, G.C. Farlow, C.J. Mchargue, P.S. Sklad, M.P. Angelini, and B.R. Appleton, Nucl. Instrum. Methods B $7 / 8,473$ (1985).

8. C.W. White, P.S. Sklad, L.A. Boatner, G.C. Farlow, C.J. Mchargue, B.C. Sales, and M.J. Aziz, Mat. Res. Soc. Proc. 60, 337 (1986).

9. C.W. White, L.A. Boatner, P.S. Sklad, C.J. McHargue, S.J. Pennycook, M.J. Aziz, G.C. Farlow, and J. Rankin, Mat. Res. Soc. Proc. 74 (in press).

10. See for example: J. Marayan, O.W. Holland, and B.R. Appleton, J. Vac. Sci. Technol. B 1,871 (1983), and references contained therein. 